\title{
A Double-Masked, Placebo-Controlled Study of Fluoxetine for Hypochondriasis
}

\author{
Brian A. Fallon, MD, MPH,* Eva Petkova, PhD, $\dagger$ Natalia Skritskaya, PhD,* \\ Arturo Sanchez-Lacay, MD,* Franklin Schneier, MD,* Donna Vermes, RN, LNP,* \\ Jianfeng Cheng, MD, PhD, $\dagger$ and Michael R. Liebowitz, MD*
}

\begin{abstract}
This study assessed the efficacy, durability, and tolerability of fluoxetine for hypochondriasis, a disorder for which controlled pharmacological trials are scarce.

Fifty-seven patients with hypochondriasis were enrolled: 12 discontinued during the placebo run-in, and 45 were randomized to either fluoxetine or placebo for 12 weeks (acute treatment). Responder status was defined as a Clinical Global Impression rating for hypochondriasis of much or very much improved. Secondary outcome measures included severity of hypochondriasis, somatization, anxiety, and depression. Responders to acute treatment entered a 12-week maintenance phase to week 24. Sustained responders at week 24 entered a 12-week double-masked discontinuation phase. Primary analysis used the intent-to-treat sample.
\end{abstract}

More patients responded with improvement in hypochondriasis when given fluoxetine compared with placebo, starting at week 8 (50.0\% vs $19.0 \%, P=0.03)$ and continuing to week $12(62.5 \%$ vs $33.3 \%, P=0.05$ ). Mean dose at week 12 dose was $51.4 \mathrm{mg}$ (SD, $\pm 23 \mathrm{mg}$ ). The acute treatment response was maintained to week 24 with more responders in the fluoxetine compared with the placebo group $(54.2 \%$ vs $23.8 \%, P=0.04)$. Significant improvement was not noted on the continuous secondary outcomes measures of hypochondriasis, with the exception of the Clinical Global Impression hypochondriasis severity scale at week 24 . Likelihood of response was not associated with severity of psychiatric comorbidity. Durability of response after controlled drug discontinuation could not be reasonably assessed, given the small sample size of patients who entered the discontinuation phase $(n=10)$. Fluoxetine was well tolerated, with no significant differences in discontinuation due to side effects between treatment groups.

Fluoxetine is a moderately effective and well-tolerated treatment for hypochondriasis.

Departments of *Psychiatry and †Biostatistics, Columbia University, New York, NY.

Received February 23, 2008; accepted after revision September 2, 2008.

This study was supported by a "First Award" (R29 MH49409) from NIHM to Dr Fallon.

This study was presented at the International Congress on Somatoform Disorders, Marburg, Germany, February 21-24, 2002.

Location of work: New York State Psychiatric Institute in Manhattan, NY (main site), and the Freedom From Fear Clinic, Brooklyn, NY, and St Joseph's Medical Center, Stamford, CT (secondary).

Fluoxetine was provided at no cost by Eli Lilly, Co.

Address correspondence and reprint requests to Brian A. Fallon, MD, MPH, Department of Psychiatry, Columbia University, 1051 Riverside Dr, Unit 69, New York, NY 10032. E-mail: baf1@columbia.edu.

Copyright (C) 2008 by Lippincott Williams \& Wilkins

ISSN: 0271-0749/08/2806-0638

DOI: $10.1097 / \mathrm{JCP} .0 \mathrm{~b} 013 \mathrm{e} 31818 \mathrm{~d} 21 \mathrm{cf}$

\section{(J Clin Psychopharmacol 2008;28:638-645)}

$\mathrm{H}$ ypochondriasis, a chronic and disabling disorder, affects $4 \%$ to $6 \%$ of patients in primary care settings. ${ }^{1-4}$ Both Diagnostic and Statistical Manual of Mental Disorders, Revised Third Edition (DSM-III-R) and Diagnostic and Statistical Manual of Mental Disorders, Fourth Edition (DSM-IV) define hypochondriasis as a preoccupation with the fear or belief that one has a serious disease based on a misinterpretation of bodily symptoms that persists for at least 6 months despite appropriate medical evaluation or reassurance and which causes either clinically significant distress or functional impairment. These patients respond poorly to standard medical management, often receive unnecessary tests or medical care, and are perceived by physicians as reluctant to accept a psychotherapy referral. ${ }^{5,6}$

Despite its prevalence and adverse personal and public health impact, hypochondriasis has only recently been the subject of controlled treatment studies. These studies indicate that cognitive behavioral therapy can be helpful for patients with hypochondriasis. ${ }^{7,8}$ However, there has been only 1 prior placebo-controlled pharmacotherapy study ${ }^{9}$; this study demonstrated the short-term effectiveness of paroxetine, a selective serotonin reuptake inhibitor (SSRI), for the completer sample but not for the intent-to-treat (ITT) sample. No study has yet reported the durability of response to a pharmacological agent among treatment responders, and there have been no controlled studies of other medications.

This randomized, double-masked, placebo-controlled clinical trial was conducted to evaluate both the short- and long-term efficacy and tolerability of treatment with fluoxetine for hypochondriasis. Fluoxetine was chosen for 3 reasons. First, a serotonin reuptake inhibitor should be effective for the obsessional aspects of hypochondriasis. Second, fluoxetine is generally well tolerated with few side effects. Third, earlier uncontrolled research using fluoxetine indicated that as many as $70 \%$ of patients are at least much improved after 12 weeks of treatment. ${ }^{10}$

\section{METHODS}

\section{Study Participants}

Between 1993 and 2000, individuals with a history of hypochondriasis between the ages of 18 and 75 years were recruited from primary care clinic screenings, physician 
mailings, and media announcements. The study was approved by the human subjects committees at the New York State Psychiatric Institute and Columbia University. After complete description of the study to the subjects, written informed consent was obtained. Evaluation and outpatient treatment were conducted at the New York State Psychiatric Institute, at the Freedom From Fear Clinic in Brooklyn, NY (a freestanding community mental health clinic), or at the Family Medicine Center at St Joseph's Medical Center in Stamford, CT. Participants were eligible if they met the DSM-III-R (later $D S M-I V$ ) criteria for hypochondriasis, had a severity of hypochondriasis that was rated as at least "moderate" on the Clinical Global Impression-Severity scale of hypochondriasis, ${ }^{11}$ were willing to be free of psychiatric medications for at least 2 weeks before randomization, and were able to provide written informed consent. Excluded were participants with other current primary Axis I psychiatric disorders, a current Axis II diagnosis of antisocial personality disorder, a lifetime psychotic or bipolar disorder, prominent suicidal ideation within the preceding 6 months, an unstable major medical illness, or an uncertain current medical condition. For patients with a current medical problem, the patient's doctor had to agree that the medical problem was stable and that the patient's concerns about his/her medical problem were excessive. Access to other physicians or health care providers was not restricted during the treatment phase of this study.

\section{Study Design}

Patients with a primary diagnosis of hypochondriasis were enrolled in a 36-week trial, consisting of three 12-week double-masked phases: acute (phase 1), maintenance (phase 2), and discontinuation (phase 3) Before initial randomization, all patients received single-masked placebo, 1 pill per day, for the first 2 weeks of the study to exclude patients with poor compliance or an early placebo response. Patients rated as nonresponders by an independent evaluator (IE) at the end of the placebo run-in phase were randomized to fluoxetine or matching placebo capsules. Patients rated by the IE as responders at the end of phase 1 (week 12) continued into phase 2 while maintaining the same number of study pills. Nonresponders at the end of phase 1 or patients who reverted to nonresponse at the end of phase 2 (week 24) were removed from the study and treated openly. Patients rated as responders at the end of phase 2 entered the discontinuation phase, in which patients on placebo continued on placebo, whereas patients on fluoxetine were randomly assigned to either placebo or continued fluoxetine (Fig. 1).

\section{Acute Treatment}

Dosing of fluoxetine and matching placebo started at 1 pill or $20 \mathrm{mg}$ daily and increased by $20 \mathrm{mg} / \mathrm{d}$ every 2 weeks, as needed and tolerated, to a maximum dose of $80 \mathrm{mg} / \mathrm{d}$. Patients met with a study psychiatrist weekly for the first 4 weeks and every 2 weeks thereafter. During each study visit, the doctor reviewed the patient's side effects using a side effect checklist, reviewed illness-related experiences using a daily diary, and adjusted medication dose accordingly.

\section{Maintenance Phase}

Responders at week 12 who agreed to continue in the study continued on the same treatment and met with the psychiatrist monthly.

\section{Discontinuation Phase}

At week 24, some patients on fluoxetine received a week 24 randomization that required a switch to placebo. This switch was done in a masked fashion without changing the number of pills and without a taper. Other patients stayed on the same treatment as in the maintenance phase. Monthly study visits with the psychiatrist continued.

\section{Randomization}

Patients were assigned in a 1:1 ratio to oral fluoxetine or a matching oral placebo pill using a computer-generated randomization list. The randomization was stratified with respect to current $D S M$ Axis I comorbidity (none, major depressive disorder, or dysthymia or other) and Axis II comorbidity (present/absent).

\section{Masking}

A research pharmacist, who had no contact with the patient, prepared prescriptions. The treatment randomization was masked to the patient and all clinical and research staff. To avoid inadvertent unmasking, patients were reminded not to discuss adverse events with the IEs.

\section{Sample Size}

A sample size of 56 randomized subjects provided a power of 0.86 to detect a difference in responder rate at a significance level of $P=0.05$ between drug and placebo in the ITT sample.

\section{Assessments}

\section{Screening}

At the primary care clinic site, subjects were screened for hypochondriasis using the Whiteley Index for hypochondriasis, ${ }^{12}$ with a score of 8 or more serving as the threshold to be evaluated further. Patients calling from elsewhere were screened over the telephone using the diagnostic criteria for hypochondriasis. The research psychiatrist conducted an inperson psychiatric and medical history to confirm that the patient's unexplained medical symptoms were indeed due to hypochondriasis and not due to an unattended medical problem. The interview was followed by a physical examination with electrocardiogram, urinalysis, and laboratory blood work, as well as a comprehensive diagnostic assessment using the Structured Clinical Interview for DSM-III-R (later $D S M-I V$ ) (SCID I and SCID II). (Refer to Fig. 1 for participant flow diagram.)

\section{Outcome Measures}

Participants were assessed before treatment and at weeks $4,8,12,24$, and 36 by an IE for whom treatment randomization was masked. Two IEs participated in this study, each a research nurse with several years of experience 


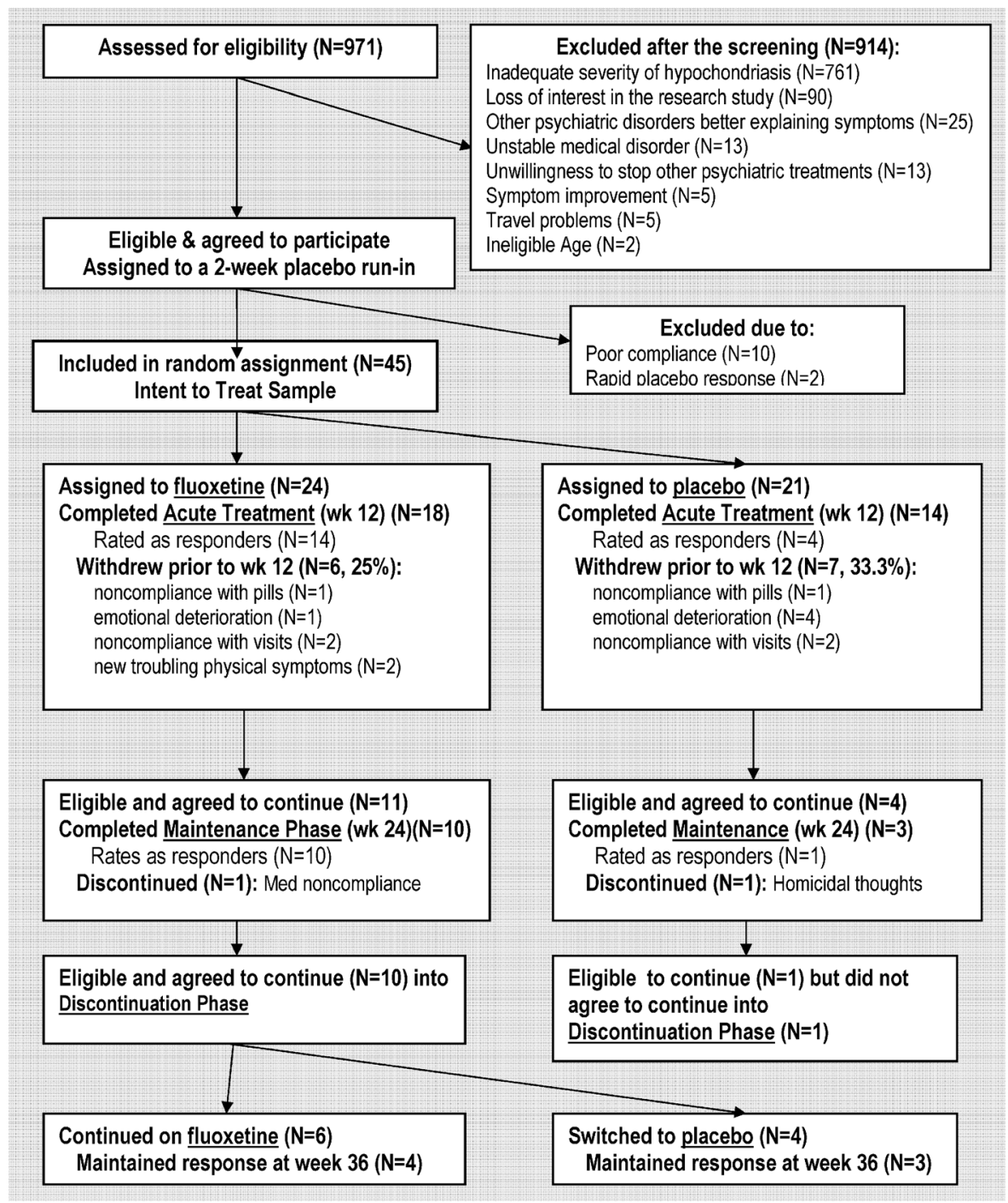

FIGURE 1. Flow diagram of the randomized fluoxetine study design.

in the evaluation of outcome in clinical trials. Interrater reliability meetings were held monthly to ensure concordance between raters. The primary outcome measure was the Clinical Global Impression ${ }^{13}$ of change in hypochondriasis as rated by the IE. A "responder" was defined based on a rating of "very much improved" (virtual remission of hypochondriasis) or "much improved" (clinically significant improvement). The primary end point for the acute phase was week 12 . Other hypochondriasis-specific assessments included the IEadministered measures (the Heightened Illness Concern [HIC] Severity Scale ${ }^{11}$ and the Columbia Heightened Illness Concern-Obsessive-Compulsive Scale [CHIC-OCS]), a hypochondriasis-focused adaptation of the well-standardized Yale-Brown Obsessive Compulsive Scale, an obsessivecompulsive disorder [OCD] rating scale ${ }^{14}$ ) and the self-report Whiteley Index. ${ }^{12}$ The HIC Severity Scale, the CHIC-OCS, and the Whiteley Index were examined both as continuous measures to describe magnitude of improvement at the end of each phase compared with baseline and as categorical measures to identify patients who improved at least $25 \%$ over the baseline score. Other psychopathology was assessed by the Somatic Symptom Inventory (SSI), ${ }^{15,16}$ Beck Depression Inventory (BDI), ${ }^{17}$ the Hamilton Depression Scale (HAM-D) (24 items), ${ }^{18}$ and the Hamilton Anxiety Scale (HAM-A). ${ }^{19}$

\section{Statistical Analyses}

The primary analysis involved the ITT sample, which included all subjects who were randomized into phase 1 . Secondary analyses examined the response of subjects who received at least 6 weeks of treatment ("minimum-treatment completers") and subjects who completed all 12 weeks of study medication ("acute-phase completers"). For subjects leaving the study before completion, ratings at the time of termination or, if unavailable, their most recent postrandomization ratings were used as their end-of-treatment assessment. Patients for whom a postrandomization IE rating could not be obtained (ie, in patients who dropped out in the first 3 weeks and would not return for a termination IE rating) were considered nonresponders. Categorical outcome was 


\begin{tabular}{|c|c|c|c|c|}
\hline \multirow[b]{2}{*}{ Characteristics } & \multicolumn{2}{|c|}{$\begin{array}{c}\text { Fluoxetine } \\
\text { Group }(n=24)\end{array}$} & \multicolumn{2}{|c|}{$\begin{array}{c}\text { Placebo } \\
\text { Group }(n=21)\end{array}$} \\
\hline & Mean & SD & Mean & SD \\
\hline Age, yrs & 37.8 & 9.2 & 39.6 & 12.2 \\
\hline Age at onset, yrs & 30.6 & 10.1 & 29.2 & 14.0 \\
\hline Duration of hypochondriasis, yrs & 8.0 & 7.9 & 10.2 & 9.7 \\
\hline Whiteley Index & 50.4 & 12.6 & 53.2 & 8.9 \\
\hline HIC Severity Scale & 5.0 & 0.7 & 4.9 & 0.8 \\
\hline CHIC-OCS & 19.1 & 7.0 & 17.7 & 6.4 \\
\hline SSI & 58.3 & 17.1 & 67.4 & 19.7 \\
\hline BDI & 16.4 & 12.7 & 16.4 & 11.1 \\
\hline HAM-D & 14.8 & 5.8 & 12.5 & 6.4 \\
\hline \multirow[t]{2}{*}{ HAM-A } & 15.5 & 6.6 & 13.9 & 5.1 \\
\hline & $\mathbf{n}$ & $\%$ & $\mathbf{n}$ & $\%$ \\
\hline Female sex & 12 & 50.0 & 13 & 61.8 \\
\hline \multicolumn{5}{|l|}{ Education } \\
\hline No more than high school & 9 & 37.5 & 7 & 33.3 \\
\hline $\begin{array}{l}\text { Post-high school education but } \\
\text { no degree }\end{array}$ & 8 & 33.3 & 7 & 33.3 \\
\hline Degree or more & 7 & 29.2 & 7 & 33.3 \\
\hline \multicolumn{5}{|l|}{ Frequency of doctor visits } \\
\hline$<4$ times in last year & 6 & 25.0 & 5 & 23.8 \\
\hline $4-11$ times in last year & 7 & 29.2 & 5 & 23.8 \\
\hline At least once a month & 11 & 45.8 & 10 & 47.6 \\
\hline \multicolumn{5}{|c|}{ No. different doctors seen in last year } \\
\hline No more than 1 doctor & 8 & 33.3 & 5 & 23.8 \\
\hline $2-5$ doctors & 8 & 33.3 & 13 & 61.8 \\
\hline$>5$ different doctors & 8 & 33.3 & 3 & 14.3 \\
\hline \multicolumn{5}{|l|}{ Axis I comorbidity } \\
\hline None & 6 & 25.5 & 7 & 33.3 \\
\hline Major depression/dysthymia & 14 & 58.3 & 8 & 38.1 \\
\hline Other & 4 & 16.7 & 6 & 28.6 \\
\hline \multicolumn{5}{|l|}{ Axis II comorbidity } \\
\hline None & 13 & 54.2 & 11 & 52.4 \\
\hline At least $1 D S M$ Axis II diagnosis & 11 & 45.8 & 10 & 47.6 \\
\hline
\end{tabular}

analyzed using $\chi^{2}$ test for independence, and continuous outcome was analyzed using 2-sample $t$ tests to evaluate percentage improvement compared with baseline scores.

To assess the effect of various baseline covariates (depression [HAM-D, BDI], anxiety [HAM-A], somatization [SSI], comorbid Axis I depressive disorder [DSM depression or dysthymia], comorbid personality disorders [SCID II], and duration of illness) on the treatment outcome, response status was modeled as a function of treatment, a covariate, and treatment-by-covariate interaction using logistic regression; if a significant interaction effect was not found, we fitted a model involving only main effects of treatment and the covariate; separate models were fit for each of the covariates. $\alpha=0.05$.

\section{RESULTS}

\section{Screening}

Of 971 patients screened either over the telephone or in person, 57 were eligible for the study, and 914 were not eligible or not interested in research (Fig. 1). Most patients were excluded because hypochondriasis was either not present or not of sufficient severity $(\mathrm{n}=761)$ or another psychiatric disorder better accounted for the primary symptoms $(\mathrm{n}=25)$.

\section{Acute Phase}

\section{Enrollment}

Of the 57 patients who entered the study, 12 were excluded before randomization during the 2 -week placebo runin phase, 10 due to poor compliance and 2 due to a rapid placebo response. Of the 45 randomized patients (the ITT sample), 37 (82.2\%) completed at least 6 weeks of pharmacological treatment (minimum-treatment completers), and $32(71.1 \%)$ completed the full 12 weeks of acute treatment (acute-phase completers).

\section{Description of the Randomized Sample}

The average age was 39.5 years (SD, 11.2 years; range, 19-70 years), equally distributed by sex ( 20 men and 25 women). The sample was $84.2 \%$ white, $10.5 \%$ black, $1.8 \%$ Asian, and $3.5 \%$ other. Ethnically, $45.6 \%$ were Hispanic, and $54.4 \%$ were non-Hispanic. In respect to Axis I disorders, the study sample had $28.9 \%$ with primary hypochondriasis alone, $48.9 \%$ with primary hypochondriasis and a secondary depressive disorder, and $22.2 \%$ with primary hypochondriasis and another non-depression-related major Axis I disorder. On Axis II, $46.6 \%$ had at least 1 comorbid personality disorder. Among the 21 patients with personality disorders, the mean number of Axis II disorders was 2.7 (SD, 1.9) with a range of 1 to 7 . The most common personality disorders among these 21 patients were avoidant $(42.9 \%)$, paranoid $(38.1 \%)$, and borderline (23.8\%). Patients' primary disease worry varied widely, but most common among the 45 subjects was the fear or conviction of having cancer $(37.7 \%)$, heart disease $(15.5 \%)$, and AIDS (13.3\%). On the HIC Severity Scale, $18.2 \%$ experienced severe

TABLE 2. Responder Status at Week 12 on CGI Change Rating by IE

\begin{tabular}{|c|c|c|c|c|c|c|}
\hline \multirow[b]{2}{*}{ Sample } & \multicolumn{2}{|c|}{$\begin{array}{c}\text { Drug } \\
\text { Responder }\end{array}$} & \multicolumn{2}{|c|}{$\begin{array}{l}\text { Placebo } \\
\text { Responder }\end{array}$} & \multirow[b]{2}{*}{$\chi^{2}$} & \multirow[b]{2}{*}{$P$} \\
\hline & $\mathbf{n}$ & $\%$ & $\mathbf{n}$ & $\%$ & & \\
\hline \multicolumn{7}{|l|}{ ITT $(\mathrm{n}=45)$} \\
\hline Wk 4 & $9 / 24$ & 37.5 & $6 / 21$ & 28.6 & 0.40 & 0.53 \\
\hline Wk 8 & $12 / 24$ & 50.0 & $4 / 21$ & 19.0 & 4.68 & 0.03 \\
\hline Wk 12 & $15 / 24$ & 62.5 & $7 / 21$ & 33.3 & 3.8 & 0.05 \\
\hline $\begin{array}{l}\text { Minimum } \\
\text { treatment }(\mathrm{n}=37)\end{array}$ & $15 / 21$ & 71.4 & $5 / 16$ & 31.3 & 5.90 & 0.02 \\
\hline $\begin{array}{l}\text { Acute-phase } \\
\text { completer }(\mathrm{n}=32)\end{array}$ & $14 / 18$ & 77.8 & $4 / 14$ & 28.6 & 7.75 & 0.005 \\
\hline
\end{tabular}


or extreme hypochondriasis, 52.3\% marked hypochondriasis, and $29.6 \%$ moderate hypochondriasis. (Refer to Table 1 for the demographics and clinical ratings on baseline measures by treatment group; no significant differences were noted between groups on these measures).

\section{Dropouts}

Of the 45 randomized subjects, $6(25 \%)$ of the 24 patients assigned to fluoxetine and 7 (33.3\%) of the 21 patients assigned to placebo dropped out before the end of the acute phase. Comparing drug versus placebo, reasons for dropout included noncompliance with pills (1/24 vs $1 / 21)$, emotional deterioration ( $1 / 24$ vs $4 / 21)$, noncompliance with visits $(1 / 24$ vs $1 / 21)$, moved/never returned (1/24 vs $1 / 21)$, and new troubling physical symptoms ( $2 / 24$ vs $0 / 21)$. In only 2 of the 6 fluoxetine-randomized dropouts was the cause attributed to the study drug; 1 patient developed gastrointestinal distress, and the other developed tachycardia after starting the drug.

\section{Outcome}

\section{Effect of Treatment on Responder/Nonresponder Status}

At week 12, fluoxetine was significantly more effective than placebo in the ITT sample, the minimum-treatment sample, and the acute-phase completer sample (Table 2). The responder rate for the ITT sample was nearly twice as great for those patients randomized to fluoxetine $(62.5 \%)$ as compared with placebo $(33.3 \%)$. This pattern of more responders in the fluoxetine-treated group versus placebo was also seen at week 8 but not at week 4 . When examining the subgroup of ITT responders who were virtually free of hypochondriasis at week 12 (ie, rated as "very much improved" on the CGI scale), a trend was seen such that the proportion of hypochondriasis-free patients was 3.5 times greater in the fluoxetine group than in the placebo group (8/ 24 vs $2 / 21$, Fisher exact test $P=0.08$ ). If instead of carrying the last rating forward, we used the more conservative imputation method and assume that all patients not rated were nonresponders, then the ITT responder rate at week 12 would be $14(58.3 \%)$ of 24 for fluoxetine versus $4(19.0 \%)$ of 21 for placebo $\left(\chi_{1}^{2}=7.2, P=0.007\right)$.

\section{Effect of Treatment on Secondary \\ Hypochondriasis-Specific Outcome Measures}

When the secondary hypochondriasis scales (CHICOCS, the HIC-Severity, and the Whiteley Index) were evaluated as continuous measures, the drug-treated group consistently had greater improvement than the placebo group, but the difference was at the margin of significance only for the completer sample on the CHIC-OCS at week $12(P=0.05)$ (Table 3$)$. The treatment effect size was mild to moderate for the ITT sample and mild to large for the week 12 completer sample. When these same measures were evaluated categorically to compare the proportion of patients who improved at least $25 \%$ over baseline, no significant differences between drug and placebo groups were noted in the ITT or completer samples. In a post hoc analysis, we applied the more conservative convention used in OCD research of requiring the definition of response to include both a CGI improvement rating of 1 or 2 (ie, responder) and a dimensional improvement of at least $25 \%$ on the CHIC-OCS; using this approach, the drug-treated group

TABLE 3. Ratings on Secondary Outcome Measures at Week 12 as Compared With Baseline

Continuous Analysis: Percentage Improvement in Scores at Week 12 Compared With Baseline

\begin{tabular}{|c|c|c|c|c|c|c|c|c|c|c|c|c|c|c|c|c|}
\hline \multirow{3}{*}{$\frac{\text { Secondary Outcome }}{\text { Measures }}$} & \multicolumn{8}{|c|}{ ITT Sample } & \multicolumn{8}{|c|}{ Week 12 Completer Sample } \\
\hline & \multicolumn{2}{|c|}{$\begin{array}{c}\text { Drug } \\
(n=24)\end{array}$} & \multicolumn{2}{|c|}{$\begin{array}{l}\text { Placebo } \\
(n=21)\end{array}$} & \multirow[b]{2}{*}{$t$} & \multirow[b]{2}{*}{$d f$} & \multirow[b]{2}{*}{$\boldsymbol{P}$} & \multirow[b]{2}{*}{ ES } & \multicolumn{2}{|c|}{$\begin{array}{c}\text { Drug } \\
(\mathrm{n}=\mathbf{1 8})\end{array}$} & \multicolumn{2}{|c|}{$\begin{array}{l}\text { Placebo } \\
(n=14)\end{array}$} & \multirow[b]{2}{*}{$t$} & \multirow[b]{2}{*}{$d f$} & \multirow[b]{2}{*}{$\boldsymbol{P}$} & \multirow[b]{2}{*}{ ES } \\
\hline & $\mathbf{M}$ & SD & $\mathbf{M}$ & SD & & & & & $\mathbf{M}$ & SD & $\mathbf{M}$ & SD & & & & \\
\hline CHIC-OCS & 38.2 & 36.9 & 22.7 & 28.1 & 1.6 & 43 & 0.13 & 0.55 & 48.8 & 30.9 & 26.5 & 31.6 & 2.01 & 30 & 0.05 & 0.71 \\
\hline HIC Severity & 24.6 & 25.3 & 16.8 & 21.0 & 1.1 & 43 & 0.27 & 0.37 & 30.0 & 24.9 & 19.9 & 23.6 & 1.17 & 30 & 0.25 & 0.43 \\
\hline Whiteley Index & 21.3 & 24.4 & 13.9 & 23.1 & 1.0 & 43 & 0.31 & 0.32 & 27.0 & 25.2 & 20.5 & 26.0 & 0.71 & 30 & 0.48 & 0.25 \\
\hline
\end{tabular}

Categorical Analysis: Percentage of Patients Who Improved at Least 25\% Over Baseline at Week 12

\begin{tabular}{|c|c|c|c|c|c|c|c|c|c|c|c|c|}
\hline \multirow[b]{3}{*}{ Outcome } & \multicolumn{6}{|c|}{ ITT Sample } & \multicolumn{6}{|c|}{ Week 12 Completer Sample } \\
\hline & \multicolumn{2}{|c|}{$\begin{array}{c}\text { Drug } \\
(n=24)\end{array}$} & \multicolumn{2}{|c|}{$\begin{array}{l}\text { Placebo } \\
(\mathrm{n}=21)\end{array}$} & \multirow[b]{2}{*}{$x x^{2}$} & \multirow[b]{2}{*}{$P$} & \multicolumn{2}{|c|}{$\begin{array}{c}\text { Drug } \\
(\mathrm{n}=18)\end{array}$} & \multicolumn{2}{|c|}{$\begin{array}{l}\text { Placebo } \\
(n=14)\end{array}$} & \multirow[b]{2}{*}{$\chi^{2}$} & \multirow[b]{2}{*}{$P$} \\
\hline & $\mathbf{n}$ & $\%$ & $\mathbf{n}$ & $\%$ & & & $\mathbf{n}$ & $\%$ & $\mathbf{n}$ & $\%$ & & \\
\hline CHIC-OCS & 16 & 66.7 & 10 & 47.6 & 1.66 & 0.20 & 15 & 83.3 & 7 & 50.0 & 4.07 & 0.06 (FET) \\
\hline HIC Severity Scale & 11 & 45.8 & 7 & 33.3 & 0.73 & 0.39 & 10 & 55.6 & 5 & 35.7 & 1.25 & 0.27 \\
\hline Whiteley Index & 13 & 54.2 & 7 & 33.3 & 1.97 & 0.16 & 12 & 66.6 & 7 & 50.0 & 0.91 & 0.34 \\
\hline
\end{tabular}

FET indicates Fisher exact test; ES, effect size. 
was shown to have a greater proportion of responders than the placebo group in both the ITT sample (14/24 vs $5 / 21$; $\left.\chi_{2}^{2}=5.5, P=0.02\right)$ and the completer samples $(13 / 18$ vs $3 / 14$; $\left.\chi_{1}^{2}=8.1, P<0.01\right)$.

\section{Effect of Baseline Covariates on Responder/Nonresponder Status}

Axis I and II Comorbidity. The effect of treatment on response status did not depend on Axis I or Axis II comorbidity: there was no significant interaction between comorbidity measures and treatment assignment in the logistic regression models for response. Because patient randomization was stratified based on comorbidity, Axis I and Axis II comorbidity was equally distributed across treatment groups.

Other Covariates. Using a logistic regression analysis, other covariates that might be expected to have an impact on treatment response were also examined, such as age, sex, baseline scores on general hypochondriasis (Whiteley, CHICOCS, HIC-Severity), intensity of somatic symptoms (SSI), depression (BDI, 24-item HAM-D), and anxiety (HAM-A). None of these covariates modified the effect of treatment, as no treatment-by-covariate interaction effect on response was noted.

\section{Effect of Treatment on Psychopathology}

No significant differences between the drug and placebo groups were noted for the ITT or the completer samples on the continuous measures of depression (BDI and HAM-D), anxiety (HAM-A), or somatization (SSI).

\section{Relationship Between Fluoxetine Dose, Response Status, and Dropout}

The mean final dose was $51.4 \mathrm{mg}(\mathrm{SD}, 23.0 \mathrm{mg}$ ), and the median final dosage was $50 \mathrm{mg} / \mathrm{d}$. Maximum dose reached was $20 \mathrm{mg} / \mathrm{d}$ for $23 \%$ of sample, $40 \mathrm{mg} / \mathrm{d}$ for $27 \%$, $60 \mathrm{mg} / \mathrm{d}$ for $23 \%$, and $80 \mathrm{mg} / \mathrm{d}$ for $27 \%$. As would be expected with a flexibly dosed study, no significant relationship was noted between final maximal dose and degree of symptom improvement. Although a higher dropout rate was noted among patients whose last dose was $20 \mathrm{mg}$ compared with higher doses ( $80 \%$ vs $11.8 \%$ dropout), this is likely due to the fact that patients were most likely to discontinue during the first few weeks of the study when the dose was lowest.

\section{Maintenance Phase}

Of the 18 patients ( $14 \mathrm{drug} / 4$ placebo) who were rated as responders after completing 12 weeks of treatment, 15 agreed to enter the double-masked maintenance phase (11 on fluoxetine and 4 on placebo). Of the 3 fluoxetine responders at week 12 who did not continue into the maintenance phase, 2 were feeling so much better that they felt further participation in the study was not needed and 1 responder had to be withdrawn from the study due to a pharmacy error in which the patient was mistakenly advanced to the discontinuation phase. During the maintenance period, 2 subjects dropped out before week 24 (1 for homicidal thoughts on placebo and 1 for noncompliance on active drug). Of the 13 who completed 24 weeks of treatment, 10 of 10 subjects on drug and 1 of 3 subjects on placebo maintained their response. For the ITT sample, at the end of the maintenance phase, there continued to be significantly more responders in the fluoxetine group $(\mathrm{n}=$ $13 / 24[54.2 \%])$ than in the placebo group $(n=5 / 21[23.8 \%])$ $\left(\chi^{2}{ }_{1}=4.4, P=0.04\right)$. Using a more conservative imputation method, the ITT responder rate at week 24 would be 10 $(41.7 \%)$ of 24 for fluoxetine versus 1 (4.8\%) of 21 for placebo $\left(\chi_{1}^{2}=8.3, P=0.004\right)$. Also notable is that more patients randomized to fluoxetine remained in the study to week $24(10 / 24,41.7 \%)$ than patients randomized to placebo $(3 / 21,14.3 \%)\left(\chi^{2}{ }_{1}=4.3, P=0.04\right)$. For the ITT sample at week 24, patients randomized to fluoxetine showed greater percentage improvement in hypochondriasis compared with baseline than those randomized to placebo on the HIC Severity Scale (30.1 [SD, 30.3] vs 14.9 [SD, 19.6]; $t=2.0$, $P=0.05$, effect size $d=0.6$ ).

\section{Discontinuation Phase}

Of the 11 patients ( $10 \mathrm{drug} / 1$ placebo $)$ with a sustained response at week 24, 1 in the placebo group discontinued after the week 24 rating, leaving 10 subjects to enter the double-masked discontinuation phase, all of whom had been initially randomized to drug. Of these 10 subjects, 6 continued on drug, and 4 were switched to placebo. Of the 6 maintained on drug, 4 sustained their response to week 36, 1 became a nonresponder, and 1 was lost to follow-up. Of the 4 initially on drug who were switched to placebo at week 24, 3 maintained their response to week 36 and 1 was a nonresponder. In sum, 7 of the 10 patients sustained their response. Although there was no significant difference in ability to sustain a response between those maintained on fluoxetine and those switched to placebo, larger sample sizes are needed to assess this adequately.

\section{DISCUSSION}

This hypochondriasis efficacy study examined shortterm efficacy to 3 months and durability of efficacy among responders after maintenance treatment to 6 months. Conclusions about durability after controlled drug discontinuation could not be reasonably assessed, given the small sample of patients who entered the final 3-month phase of the study. On the primary outcome measure of clinical global improvement, fluoxetine was more effective than placebo, and this improvement was sustained over a 6-month interval. Given the distress, disability, and high utilization rate of medical services by hypochondriacal patients, identification of an effective pharmacological treatment should have a valuable public health impact.

At the primary end point of week 12, the proportion of responders to fluoxetine compared with placebo was significant for the completer and minimum-treatment samples and at the margin of significance $(P=0.05)$ for the ITT sample. In this placebo-controlled study, $62.5 \%$ of the ITT sample and $77.8 \%$ of the acute-phase completers were rated as responders at week 12 . These controlled results confirm SSRI efficacy as had been suggested by prior uncontrolled openlabel series of SSRIs for hypochondriasis. ${ }^{10,20-22}$ In this 
controlled study, patients with and without Axis I or Axis II comorbidity were equally likely to benefit. It is not possible to compare the results of this double-blind study with an earlier double-masked, placebo-controlled paroxetine study for hypochondriasis ${ }^{9}$ because of differences in definition of study responders.

The degree of improvement in hypochondriasis was moderate on average. Inability to demonstrate a significant treatment effect on the continuous measures at week 12 for the ITT sample likely reflects both the modest effect size and the small sample size. Self-report measures (such as the Whiteley Index) may also be less sensitive than clinicianadministered instruments (such as the CHIC-OCS or HIC Severity Scale), as there was a significant improvement noted on the CHIC-OCS for the week 12 completer sample and on the HIC Severity Scale for the week 24 ITT sample but not on the Whiteley Index at either time point. Similarly modest degrees of improvement on continuous measures have been reported after pharmacotherapy with SSRIs for other disorders characterized by marked obsessionality, as in OCD. ${ }^{23}$ Studies with larger sample sizes are needed to address theses issues.

Notable is that significantly more patients on fluoxetine reached the week 24 end point without dropping out and that only those randomized to fluoxetine in the acute phase sustained a long-term response during the follow-up to week 36. Among the 13 patients assessed at week 24 , all 10 of the 10 remaining fluoxetine-randomized patients continued to be rated as responders, whereas only 1 of the 3 remaining placebo-randomized patients maintained a favorable response. The study results also suggest that improvement in hypochondriasis for the fluoxetine group increased over the 6 months, as shown by the larger effect size for the percentage of improvement from baseline on the HIC Severity Scale at week 24 compared with that observed at week 12. None of the placebo-treated patients continued to week 36 , whereas 10 of the original fluoxetine-randomized patients continued to week 36 (of whom 4 of 6 maintained on drug and 3 of 4 switched to placebo sustained their improvement). Although the sample size of study completers is quite small, these results do suggest that fluoxetine treatment resulted in sustained improvement. Although it is encouraging to note that 3 of the 4 patients who were switched to placebo during the double-blind discontinuation phase maintained their response, no conclusions can be drawn about the durability of response when patients stop fluoxetine after 6 months, given the small sample size.

The fluoxetine- and placebo-treated groups had comparable rates of study withdrawal, indicating general tolerance of fluoxetine. Hypochondriacal patients who typically are wary of taking medication should be reassured by this study to learn that fluoxetine was well tolerated.

Although the design of this study has many strengths (randomized, placebo-controlled, stratified by comorbidity, IE ratings, double-masked maintenance, and discontinuation periods), the primary limitation of this study is the small sample size, which limits the power to detect statistical significance on the continuous measures. A second limitation is that the assessments at weeks 24 and 36 were conducted only on patients who had a sufficient improvement to enter the maintenance and discontinuation phases; it would have been preferable to call back all randomized subjects for evaluation at these intervals. Third, because of the flexible dosing, we cannot determine whether higher doses are more or less effective than lower doses. Fourth, it would have been valuable to have both patients and IEs guess the treatment to which they had been randomized; this would enable an assessment of inadvertent unmasking. Fifth, the results from this study may not be generalizable to all patients with hypochondriasis. The patients enrolled in this study had to have sufficient insight to recognize that their concerns about illness were excessive; otherwise, they would not have responded to the public advertisements or their primary care physician's recommendations and volunteered to participate in a treatment study for a psychiatric disorder. It cannot be inferred therefore that other patients with hypochondriasis who might not wish to see a psychiatrist and who might have lesser degrees of insight would respond as well to fluoxetine as occurred in this study sample. Finally, it would have been valuable to have included a measure in this study that assessed health care utilization to determine whether a reduction in hypochondriasis was associated with less health care use and expenditures.

In sum, psychiatrists and primary care physicians should be aware that fluoxetine seems to be a moderately efficacious and well-tolerated treatment for hypochondriasis. A trial that lasts at least 12 weeks is recommended to assess response. Although the data from this trial suggest that treatment for 6 months may be sufficient and result in sustained improvement, conclusions cannot be drawn without a larger sample size and longer follow-up interval.

\section{ACKNOWLEDGMENT}

The authors thank Robert Feinstein, MD, Joseph Connelly, MD, and Sharon Davies, RN, for their invaluable assistance with this study.

\section{AUTHOR DISCLOSURE INFORMATION}

Michael Liebowitz, MD, has consulted for Avera, AstraZeneca, Tikvah, Wyeth, Pherin, Eli Lilly, Jazz, and Zars. He has been a speaker for Wyeth and Bristol-Myers Squibb. Dr Liebowitz has had clinical trial contracts with Pfizer, GlaxoSmithKline, AstraZeneca, Forest, Tikvah, Avera, Eli Lilly, Novartis, Sepracor, Horizon, Johnson \& Johnson, Wyeth, Takeda, PGX Health, Pherin, MAP, Abbott, and Jazz. He has equity ownership in ChiMatrix LLC and the Liebowitz Social Anxiety Scale. Licensing software or Liebowitz Social Anxiety Scale with GlaxoSmithKline, Pfizer, Avera, Tikvah, Eli Lilly, Indevus, and Servier. No conflicts of interest are reported by the other authors.

\section{REFERENCES}

1. Barsky AJ, Wyshak G, Klerman GL, et al. The prevalence of hypochondriasis in medical outpatients. Soc Psychiatry Psychiatr Epidemiol. 1990;25:89-94.

2. Kellner R, Abbott P, Pathak D, et al. Hypochondriacal beliefs and attitudes in family practice and psychiatric patients. Int $J$ Psychiatry Med. 1983;13:127-139. 
3. Escobar JI, Gara M, Waitzkin H, et al. DSM-IV hypochondriasis in primary care. Gen Hosp Psychiatry. 1998;20:155-159.

4. Noyes R, Kathol $\mathrm{R}$, Fisher $\mathrm{M}$, et al. The validity of DSM-III-R hypochondriasis. Arch Gen Psychiatry. 1993;50:961-970.

5. Lin EH, Katon W, Von Korff M, et al. Frustrating patients: physician and patient perspectives among distressed high users of medical services. J Gen Intern Med. 1991;6:241-246.

6. Barsky AJ, Wyshak G, Latham KS, et al. Hypochondriacal patients, their physicians, and their medical care. J Gen Intern Med. 1991;6:413-419.

7. Barsky AJ, Ahern DK. Cognitive behavior therapy for hypochondriasis: a randomized controlled trial. JAMA. 2004;291:1464-1470.

8. Clark DM, Salkovskis PM, Hackman A, et al. Two psychological treatments for hypochondriasis, a randomized controlled trial. $\mathrm{Br} J$ Psychiatry. 1998;173:218-225.

9. Greeven A, Van Balkom AJ, Visser S, et al. Cognitive behavior therapy and paroxetine in the treatment of hypochondriasis: a randomized controlled trial. Am J Psychiatry. 2007;164:91-99.

10. Fallon BA, Liebowitz MR, Salman E, et al. Fluoxetine for hypochondriacal patients without major depression. J Clin Psychopharmacol. 1993;13:438-441.

11. Fallon BA. Pharmacologic strategies for hypochondriasis. In: Starcevic V, Lipsitt DR, eds. Hypochondriasis: Modern Perspectives on an Ancient Malady. New York, NY: Oxford University Press; 2001:329-351.

12. Pilowsky I. Dimensions of hypochondriasis. Br J Psychiatry. 1967;113: 89-93.
13. Guy W. ECDEU Assessment Manual for Psychopharmacology: Publication ADM 76-338. Washington, DC: US Department of Health, Education, and Welfare; 1976.

14. Goodman WK, Price LH, Rasmussen SA, et al. The Yale-Brown Obsessive Compulsive Scale, I: development, use, and reliability. Arch Gen Psychiatry. 1989;46:1006-1011.

15. Barsky AJ, Wyshak G, Klerman GL. Transient hypochondriasis. Arch Gen Psychiatry. 1990;47:746-752.

16. Weinstein MC, Berwick DM, Goldman PA, et al. A comparison of three psychiatric screening tests using receiver operating characteristic (ROC) analysis. Med Care. 1989;27:593-607.

17. Beck AT, Steer RA. Beck Depression Inventory Manual. San Antonio, TX: Psychological Corporation, Harcourt Brace; 1993.

18. Hamilton M. A rating scale for depression. J Neurol Neurosurg Psychiatry. 1960;23:56-62.

19. Hamilton M. The assessment of anxiety states by rating. $\mathrm{Br} \mathrm{J} \mathrm{Med}$ Psychol. 1959;32:50-55.

20. Fallon BA, Qureshi AL, Schneier FR, et al. An open trial of fluvoxamine for hypochondriasis. Psychosomatics. 2003;44:298-303.

21. Oosterban DB, van Balkom AJLM, van Boeijen CA, et al. An open study of paroxetine in hypochondriasis. Prog Neuropsychopharmacol Biol Psychiatry. 2001;25:1023-1033.

22. Kjernisted KD, Enns MW, Lander M. An open-label clinical trial of nefazodone in hypochondriasis. Psychosomatics. 2002;43:290-294.

23. Fallon BA, Mathew SJ. Biological therapies for obsessive-compulsive disorder. J Psychiatr Pract. 2000;6:113-128. 